\title{
Problems in simulating social reality: Observations on a MUD construction
}

\author{
Holin Lin \\ National Taiwan University \\ Chuen-Tsai Sun \\ National Chiao Tung University
}

\begin{abstract}
The authors look at computer-mediated simulation as an approach to studying social science issues and discuss its limitations, with the design process for a Multiple-User Dungeon (MUD) game serving as a context. Using data gleaned from interviews with the MUD designers, the authors present three findings: (a) fun is a key difference between simulations and reality, because a MUD user can always walk away from a game that is not fun but cannot walk away from difficult real-life situations; (b) simulated social systems require time and commitment from a fairly large population, which conflicts with the typical level of patience observed in most computer game players; and (c) the roles of technicians and designers as mediators in simulated social environments is an area requiring detailed study, because their attitudes toward technical constraints, social values, and stereotypes exert a strong influence on the appearance of their final products.
\end{abstract}

KEYWORDS: computer-mediated simulation; cyberspace; online game; simulated reality

The use of computer networks and computer simulations to study social science issues has so far been very limited; thus, their potential as research tools in this area has remained largely unexplored. Simulation applications in the social sciences are categorized as system modeling, computer-mediated simulation, and microsimulation. The first uses computer simulation tools and techniques to create models for the purpose of studying social system dynamics and processes. The second involves the construction of a computer-mediated environment in which users interact, allowing researchers to observe and analyze social relations and collective patterns. The third entails the creation of an artificial society by researchers who have the power to manipulate the details of individual agents and interactive rules. Here we will use the second approach to identify conditions and limitations for its use as a means of studying social science issues. Our goal is to generate suggestions for the expanded use of computer simulation programs in social science research.

To accomplish this goal, we organized and observed the development of a MultipleUser Dungeon or Multiple-User Domain (MUD) game. The original objective of this social education MUD was raising the consciousness of its users regarding gender

AUTHORS' NOTE: We thank the National Science Council of Taiwan for financial support. This research was sponsored through Project National Science Council No. NSC 91-2412-H-002-004.

SIMULATION \& GAMING, Vol. 34 No. 1, March 2003 69-88

DOI: $10.1177 / 1046878102250607$

() 2003 Sage Publications 
inequality. After presenting general design principles to the design team, we stepped back and let them work on the details. During the design process we noted several significant deviations from the original goal, and by exploring the designers' rationales behind these changes, we identified the strengths and limitations of computer-mediated simulation as a research method and educational tool. Thus, a failed attempt at creating a simulated society turned into a rich source of information for methodological considerations.

The concepts of online social interaction and computer simulation overlap in several important ways. Because the Internet is a computer-mediated medium, online interactions are embodied in a computer-mediated setting. The excitement and fun of many online games result from these interactions, either between users and the mediating computer/network system or among the users themselves. These interactions carry a sense of reality, that is, an assimilation of physical (real-world) reality or the construction of a virtual reality. Finally, because users consider online games fun and real, the games offer opportunities for participants to learn through interaction; such an approach has the potential to help users understand the complicated functions and relationships of natural or social systems.

Online game or learning site designers occasionally claim that they are capable of creating simulated reality, and many users of their products agree-consciously or otherwise. It is relatively easy for players of user-system interaction-based games (e.g., 3-D hack-and-slash games) to distinguish between a simulated environment/ situation and the physical world. However, for games that offer social settings for player interactions (e.g., a form of online Monopoly), users are more likely (but far from certain) to feel that they are dealing with real people in a neutral medium. Behind a seemingly real dual frame consisting of media and scenarios, the influence of computermediated designers is less obvious but nevertheless pervasive.

As Benedikt (2000) noted, "Cyberspace needs continuous planning and organization. The structure produced by cyberspace needs design, and those who are in charge of it called cyberspace architects" (p. 40). Accordingly, we set out to illuminate the technological and social characteristics of simulated reality by investigating decisions made by these architects. Our research questions include the following: (a) How much reality can actually be embedded in a simulation game that claims to achieve virtual reality? (b) Do simulations reflect conscious decisions to create successful games, or do they reflect their designers' understanding of social systems? and (c) Can a simulation game fulfill an educational mission and be entertaining at the same time?

Our research platform, which entails the anonymous role-playing features of a MUD, allows for versatile interactions among characters. The characteristics of anonymity and role-playing serve as the primary differences between a MUD and face-toface social rituals. MUD role-playing is instantaneous and embedded in the simulated environment. Because it allows for real-time interaction among many participants as well as for the creation of their own objects, a MUD allows for simulation within a social context while holding meaning that is broader than that found in most online games. This mix of educational and sociological goals within a single framework addresses Gonzalez and Gross's (1995) concern over how a simulation-based learning 
activity, especially one that delivers messages that go well beyond its original intent, affects students' ideological and social values.

Furthermore, although MUDs are generally similar to other online games in terms of computer-mediated interfaces and human-player interactions, the Internet adds two important factors to MUDs that strive to simulate socioeconomic realities: (a) it adds complexity, because players with diverse backgrounds are more likely to be found on Internet-based rather than local area network (LAN)-based games; and (b) it adds essential technical features for simulating social reality in terms of population scalability and response time. Regarding the second factor, additional players make it possible to initialize a broader range of socioeconomic behaviors, and multiple game servers make it possible to distribute and balance the overall system load to prevent delayed response time. The heterogeneity and scalability of our MUD benefited from its Internet-based framework.

\section{Research design}

The original motivation for this study was to develop an Internet community that taught users about gender-based social stratification via role-playing activities that involved virtual scenarios. ${ }^{1}$ In the spring of 1997, we asked six graduate and undergraduate students with extensive experience in MUD play and development to collaboratively design an educational MUD to meet our purposes. The most important instruction given to the designers was that the MUD should copy as much as possible the status quo of gender roles in Taiwanese society. ${ }^{2}$

We gave the designers several guiding principles of gender stratification in the physical world, then stepped aside to let them work out the details. Their consensus was that to simulate gender stratification, they first needed to simulate social scenarios because stratification is a product of social settings. From the beginning of the project, imitating reality was a clearly stated design goal. Nevertheless, as the design process evolved, the MUD gradually moved in the direction of traditional adventure games, far from our original intent. Factors that are unalterable in real life-for example, gender and physical appearance - were left to user discretion, whereas such acquired capabilities as communication skills turned into characteristics that were predetermined by the system.

It became increasingly clear that these deviations required a response on our part. The decision was made to maintain the designers' autonomy but to switch our focus from the MUD's instructional goals to the effects of the design process. The research topic was thus altered from how players in an interactive Internet community comprehend the principles of real-world social stratification to how the simulation construction process is influenced by designers' social perceptions.

Data for this study included extended interviews with the designers, the user manual posted on the MUD Web site, and discussion memos and design drafts prepared by the design team. Of the six designers-all majoring in computer science-the only female was one of four undergraduates recruited for the project; the team also included 


\section{SIMULATION \& GAMING / March 2003}

one $\mathrm{PhD}$ candidate and one graduate student. These backgrounds and the gender ratio were typical of Taiwanese MUD design teams at that time. The final product, named ETERNAL CITY (EC), was announced at a MUD workshop held in September 1997. It remained open for testing and playing until December. During the testing period, the average number of players ranged between 20 and 30 per day, with a total of approximately 100 players participating overall. Participation was voluntary, and players were free to come and go as they pleased. We found that the majority of visitors took the necessary time to explore the environment design and game rules before leaving.

This research has three implications. First, as interactive media, simulation games represent a challenge to conventional societal relationships-for instance, the traditional author-reader-text relationship — and carry the potential for reconstructing those relationships (Friedman, 1995). In other words, they carry the potential to establish a new paradigm in media study, one that would evolve separately from widely held theories on film and television. Research on computer-mediated simulation programs will play a significant role in this evolution.

Second, interactions that take place on the Internet give rise to a unique set of problems that requires study, especially in light of the roles that virtual environments and computer games may someday play in education. Research questions include the following: How can simulated games facilitate learning? What are their limitations in this regard? How much reality should be embedded in simulated educational software to help students transfer their learning to other situations and environments? and How can we be sure that simulation games remain uncontaminated by the social values and biases of their designers? Perhaps most important, we need to determine whether simulation games are more suitable for learning objectives associated with the pure sciences than with the social sciences (see Edward, 1997). As these programs are increasingly used in education, we need to take into consideration a wide array of possible loopholes, blind spots, and dead ends that could interfere with their potential as teaching tools.

Finally, we believe that games aimed at simulating reality but that gradually move away from reality raise important questions in terms of values. We need to address the issue of why a simulation game can never truly approach reality, and whether the resulting gap reflects a resistance to social reality. Specifically, does such a gap reflect differences between a designer's individual perceptions and social reality, or does it suggest that designers are bound to some currently unidentified list of functional requirements tied to interactive simulation games?

\section{Simulated reality}

As stated in the introduction, references to the use of computer simulations in the social sciences can be separated into the categories of system modeling, computermediated simulation, and all-computer or microsimulation (Gilbert, 1999; Johnson, 1999). System modeling involves the use of computer technology to construct a simulation model so that social system dynamics and processes can be studied in detail 
(Timpone \& Taber, 1998). Learning (Zola \& Ioannidou, 2000) and entertainment functions are achieved when users observe or interact with a system. Computer-mediated simulation involves the creation of an artificial environment in which users interact with each other, thus forming a problem-solving and role-playing community. Although the environment is simulated, individual participants and interactions are real. Some artificial environments simulate the real world, but others present innovative circumstances in which user recognition and behavior can be studied. Within the category of all-computer simulation, participating individuals are also artificial, with each acting as an autonomous agent. Individual behavioral models are predetermined (based on the results of other studies), and researchers observe their consequent interaction patterns and group behaviors (Artzrouni \& Gouteux, 2001). Artificial societies can also be constructed to study conditions/constraints tied to a particular theory (Holland \& Miller, 1991).

This research belongs to the computer-mediated category. A MUD offers an artificial environment in which objects, situations, and events are designed to prompt interaction among users via textual or graphical interfaces. Participants gradually construct virtual communities by identifying characters, developing interpersonal relationships, and solving problems collaboratively. Within this primary setting one finds simulated individuals (called nonperson characters [NPCs]), which is why MUDs are considered mixed computer simulation models.

As mentioned above, it is not necessary for simulated targets to be real-which is the reason why the boundary between an abstract society and a simulation game often becomes blurred. However, many computer-mediated simulations must appeal to their users' experiences in the physical world to match gaming or learning requirements. As a result, the concept of simulated reality is closely tied to virtual reality (VR) metaphors taken from multimedia technology. Occasionally, the technological attributes of VR allows users to better comprehend the sociological depths of simulated reality.

Even in their pure text form, MUDs have always been regarded as a type of VR, but today they have essentially become synonymous with online VR games; to many, they represent the highest level of computer-simulated environments. Their scenarios place pressure on individual users, thus reducing the sense of alienation that sometimes exists between themselves and artifacts in a program. Consequently, users penetrate the interface instead of interacting with it on a superficial level. Second, VR requires stronger two-way interaction than multimedia simulations and games in which one party (either the user or the system) plays a reactive role. In contrast, VR games contain a continuous series of tasks and provide immediate feedback, thus encouraging user initiative and interaction.

Third, VR games provide their users with simultaneous multiple sensory input, resulting in a more holistic experience compared with earlier versions of multimedia programs. In a virtual world, users establish their existence by moving, watching, talking, and reaching for objects at the same time. The most recent VR programs enable users to create objects for later use or for use by other players, thus promoting the simultaneous consumption and construction of the simulation. Such active participation is indispensable for creating a sense of belonging to a real society. Whereas Stuart 
(1996) argued that VR offers a compound authentic experience, we believe that MUDs achieve the highest level of VR.

However, as Johnson (1999) pointed out, many people experience some form of cognitive uncertainty about computer simulation. On one hand, users tend to be more willing to express themselves because of the anonymity and mobility of their individual identities, which enhance the real sense of a virtual community. On the other hand, simulated environments appear to become more artificial because the environment, objects, and characters are the result of design decisions. This contrast makes VR games more psychologically and sociologically complex.

\section{Research findings}

\section{The MUD environment}

EC is a simulated society filled with economic activity-for example, a sophisticated stock market, tax agency, and simplified city government. Players exchange resources, trade stock, and initiate production for the purpose of accumulating personal wealth. Unlike Monopoly and other board games, EC players do not follow predetermined routes; socioeconomic activities such as city planning, building construction, and trading are all decided cooperatively. A map of Odin City, developed by a group of players, is shown in Figure 1.

First-time users register themselves as new characters and choose the virtual communities they want to live in. ${ }^{3}$ To establish factories and warehouses, players must specify the name, type, and price of the products they wish to make and sell before searching for retail outlets. Profits can be used to buy goods, build houses, establish banks, invest in real estate, increase production, or for entertainment in casinos and other game rooms. Whenever players enter a new place, they are given a descriptive paragraph with comments on noteworthy features. Figure 2 shows the game's representation of a small pub in Odin City.

Players use various commands to check their personal belongings and properties. They say "hello" and converse with each other on occasion; friendships and partnerships are developed as production and business deals progress. An example is shown as Figure 3. Illegal activities that players can take part in include tax evasion and robbery. As in the physical world, players can get involved in such local political events as mayoral elections and city planning meetings. ${ }^{4}$

According to the MUD designers, the average EC player had a higher level of education compared to the players of other games. They explained that EC was more difficult, requiring the understanding of such advanced concepts as investment strategies. Although most of the players were college students, a significant number of high school students participated. The MUD designers occasionally entered the EC world as players because certain economic activities required larger numbers of participants; however, their participation was very much restricted by their real-world schedules and responsibilities. 


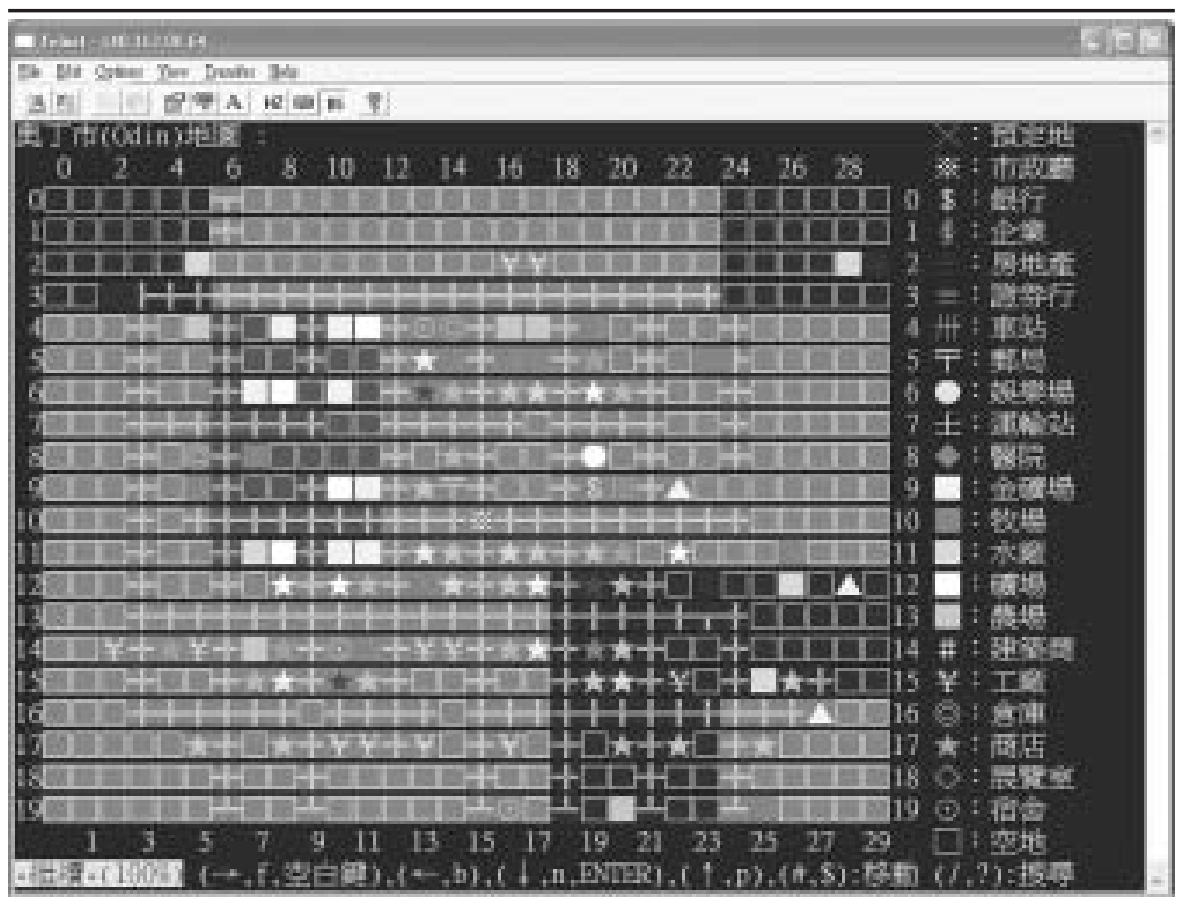

FIGURE 1: Map of Odin City

NOTE: The legend describes the various farms, factories, warehouses, shops, and institutions found within the game environment.

The focus on economic activity made EC very different from the usual array of combat-oriented MUD games that many students play. As one of the designers wrote on the EC Web site:

Because the framework of this MUD is based on economic trading, it contains factories, warehouses and shops ... each a necessary system component ... together they form a complete economic cycle. Our goal is to construct a self-contained economic society in which different kinds of relationships, either between players or between players and society, are built by the players themselves. The only responsibility of the wizards is to give the players an environment in which to develop the economic system; we do not get involved in any problems between or among players.

After the design goals were stated and clarified, the MUD developers started working on the first of three versions. The designers found it increasingly difficult to create an economy after publicly announcing their goals and testing the initial trial version. They found that price equilibrium could not be achieved by a small player population because market forces resembling those in the physical world require multiple buyers and sellers who freely participate in trading activities. As a result, they added several policy incentives (e.g., bonuses for real estate rentals) to steer players toward certain 


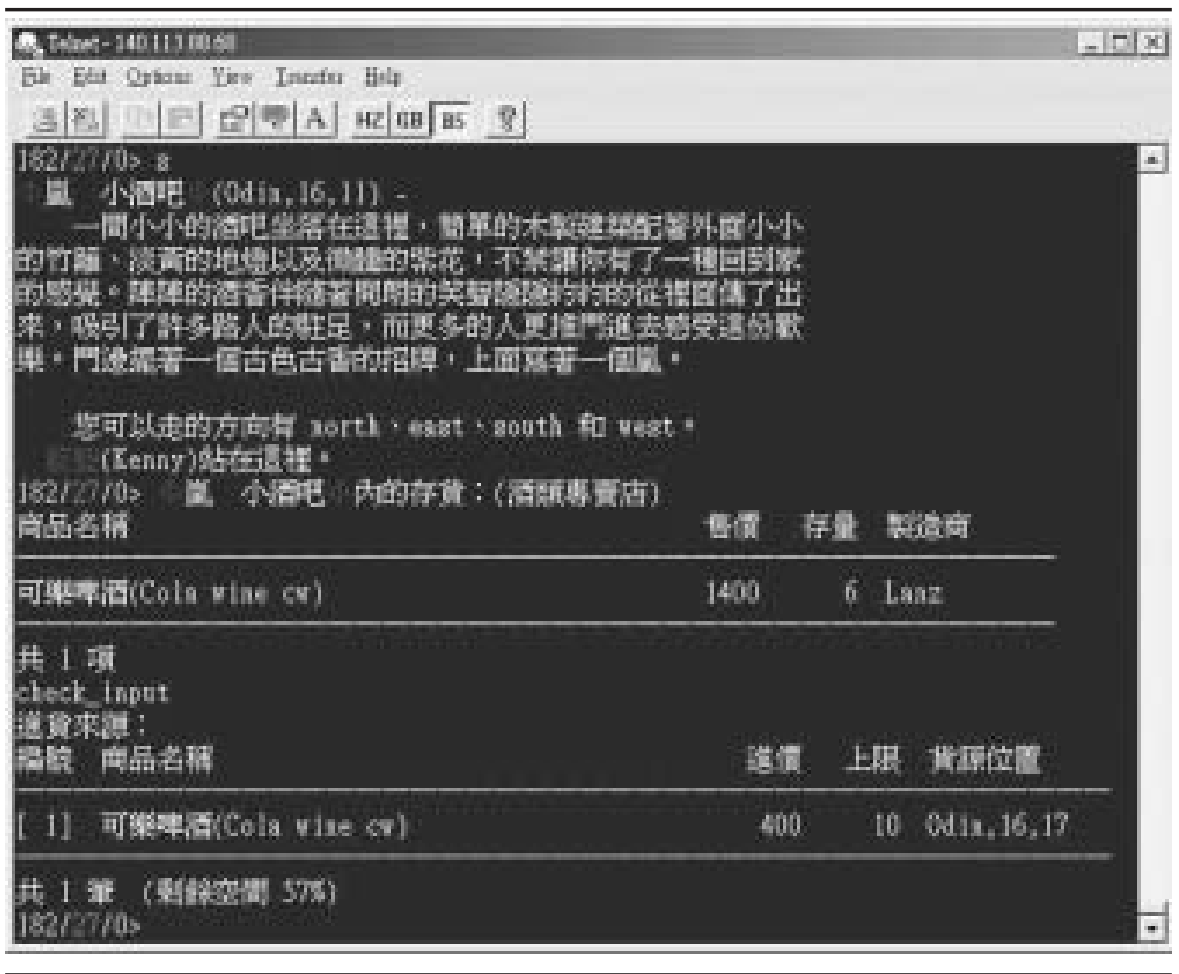

FIGURE 2: Representation of a Small Pub in Odin City

NOTE: The description shows the place name and coordinates, followed by information on a few noteworthy features of the pub. Information on the pub's stock is presented below the description.

interactions and behaviors and to maintain their interest in staying in the MUD. To keep the players focused on economic transactions, the designers established a system requiring that players purchase and drink water to earn the right to chat with others on non-MUD topics. These modifications were designed in response to the failure of certain preconditions to keep players focused on EC's main goals.

Whereas the second version of EC reflected major changes in game policy (i.e., a larger money supply), the third version was more focused on fine tuning the rules and improving efficiency. As more and more players joined, system response time became a major concern; some MUD players who felt that the system was too slow lost patience and instead tried to hack their way into the system. This serves as an example of Turkle's (1997b) comment that real-time response is the technical foundation of a life in VR. She pointed out that technical features are meant to build excitement for original participants to improve the chances that a virtual society will take on a life of its own, after which the construction of identities and reconstruction of the self becomes possible (Turkle, 1997a). 


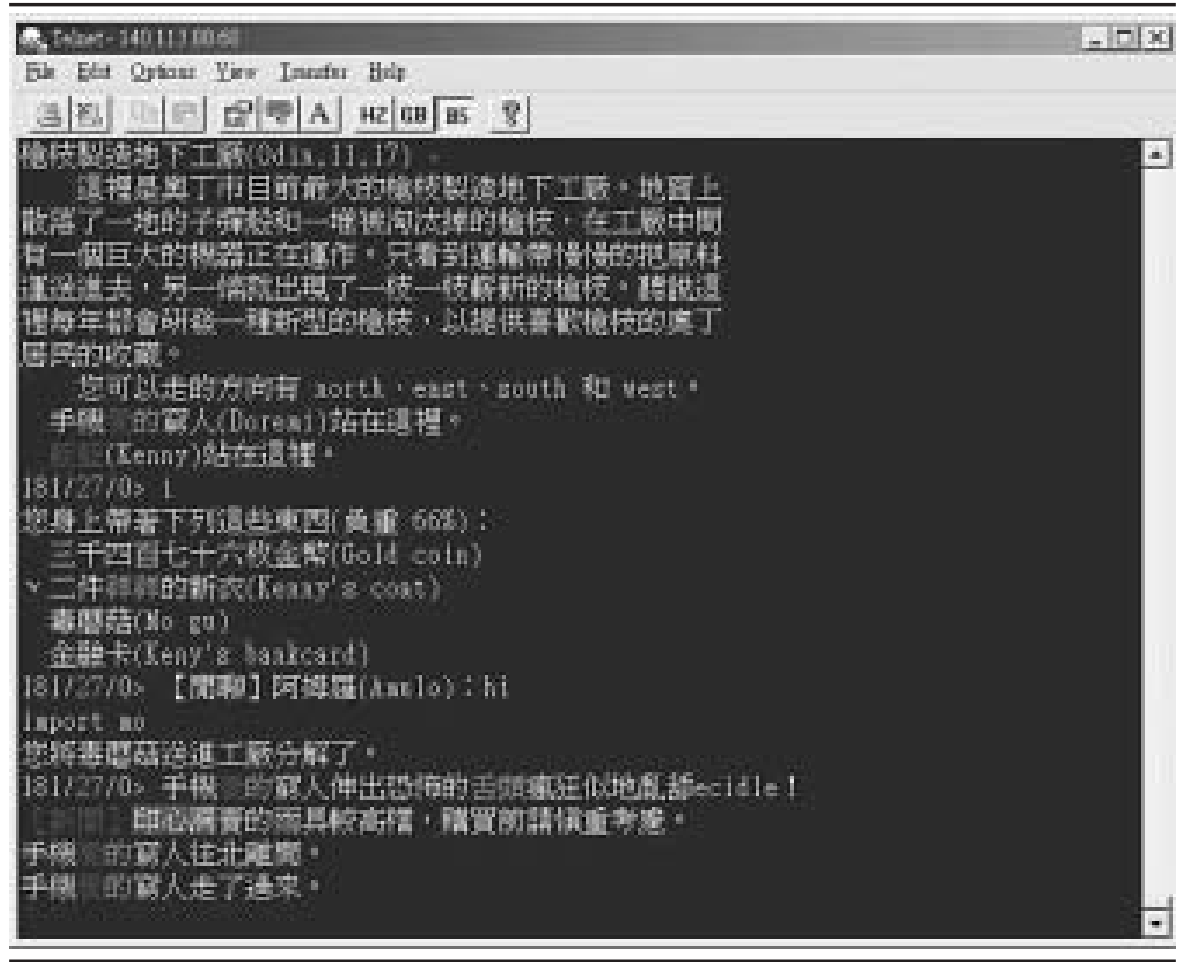

FIGURE 3: A Factory Scenario

NOTE: This is the window and scene description that a player named Kenny sees each time he enters this particular factory. The factory is used for dissolving imported objects to their component parts. After checking his belongings, Kenny is greeted by another character named Amulo. Kenny then uses an import command to dissolve some poisoned mushrooms (mo) he has collected elsewhere. Other characters visit the workplace on business, and Kenny receives occasional news broadcasts.

\section{Simulation types, levels, and limitations}

Role-playing is central to simulations and computer-mediated games. In such worlds, robots - nonhuman characters-can play multiple supportive roles. In EC, most of the government clerks are computer-programmed agents that are assigned various jobs by the system, which relieves the system manager of a very large and burdensome responsibility. Although these EC robots (who also serve as retail shop owners) are programmed to politely chat with their customers, their most important function is to check products brought in by the players and pay out the correct amount of money.

However, it is also possible to program robots to become troublesome virtual challenges. For example, look at any adventure MUD whose robots ambush players on the road to finding treasure. In EC, robots that are programmed to stop player progress come in the form of aggressive, competitive business operators. To succeed, players must develop and use problem-solving skills, which includes establishing relationships with other players. To make the game more challenging, the designers can adjust 
certain parameters to create stronger robots; even without these adjustments, the robots are programmed to evolve automatically. As Bob (a graduate student on the design team) said in an interview, EC players had to make an effort to succeed because "there will always be some monsters who are stronger than they are."

To make the game even more complex, EC players were given the option of hiring or creating their own robots. A designer named Albert, a doctoral candidate, explained that "the players need robots to play a MUD, because playing a MUD is time-consuming." Again, these player-controlled robots tended to fill such minor roles as managing factories and offices, but once players learned how to manipulate their robots, their creations started showing up in many other areas. Because the EC designers were instructed to encourage players to spend large amounts of time with the game (going so far as to measure time spent online), the players created robots to act as their surrogates in the MUD world. This eventually became a problem to be addressed because the appearance of too many robots slowed the system down.

Autonomous behavior on the part of characters invented by players is a common phenomenon in the virtual world of a MUD. Among certain groups of users, the lack of predictability associated with robots can become an interesting and fun challenge; in other cases, robots can be programmed to serve some very useful purposes. An example of the latter can be found in games that include a steal command. ${ }^{6}$ Having to constantly check your virtual possessions to make sure nothing has been stolen is a tedious chore that can lead to players leaving a game. But robots can be established and programmed by system designers to detect theft behavior and catch thieves according to probabilities built into the system. Furthermore, because human-controlled characters in EC are forbidden from acting violently, robots are sometimes programmed to perform tasks such as "beating up the thief."

The stealing and "beating up the thief" functions were used in what could be considered a very creative way by one of the EC players. The designers observed a character trying to create a formula for a drug, but felt that its health was too good to perform a self-test. The character therefore started to steal objects from other players in the hope that a robot or two would catch it in the act and beat it up, resulting in a loss of physical strength. This is an exceptional example of the type of unexpected strategies that occur within simulated societies. It also provides one possible answer to the question of why it is so difficult to simulate reality: In game situations, players do not take things very seriously. This particular character was willing to risk his or her virtual health and life because there really were no personal stakes involved.

This may explain why we observed frustration among the designers, who found it very difficult to simulate certain aspects of the physical world. One important example concerns the simulation of interpersonal relationships; the EC designers worked hard to include a family system in their MUD and offered different incentives for players to address family issues but to no avail. Albert offered this explanation:

The family system didn't work out because we couldn't keep enough players for long enough commitments. There were too few players, and they didn't know each other ... they felt that survival in EC was already hard enough. Now you want them to 
support a family! That's a large burden. You need to give your kid a lot of instructions, and give him some money. Too much sacrifice, and you don't even know that person.

The designers clearly had difficulty accepting the idea that relational networks involving two or more persons are not easily developed in simulated environmentsas is often true in the physical world. One of their most interesting reactions was the lack of a perceived need to help players develop relational networks, including families; this is especially significant within a culture that places such great emphasis on family as a cornerstone of all interpersonal relationships. Albert emphasized economic costs and benefits in his explanation, which of course reflected the emphasis on economic interactions that were central to EC. But the lack of need was explained in terms of numbers of players-with enough people in a society, some designers argued, human networks (including families) would emerge naturally. Thus, they quickly shifted their design efforts to creating such economic institutions as a stock market. According to Albert,

Family, government, and so on, these are based on common sense. But stock trading is not like that. To make it happen you have to make it real. Nowadays you watch people talking about stocks on every TV channel. But if I give you some money to buy stocks, you are doomed to lose it. The players have no knowledge about trading, placing orders, and so on.

This type of thinking resulted in the designers giving more flexibility (and therefore less simulation) to structures and relationships they believed players were more familiar with. In terms of family and government, they decided to let players develop personal or public relationships naturally, without much concern for what that meant. In contrast, for a stock market or other institution, which they believed required greater expertise than that held by the general population, they considered system-guided simulation a necessity.

Certain opinions voiced by the designers-for example, "a market needs more design than government," "a government is more natural than a market," and "a stock market is a necessity for an economic society"--deserve a closer look. On one hand, markets and other necessary elements require a high degree of simulation for successful integration into a MUD, but on the other hand, supposedly natural elements (such as governments and families) require large populations and long lead periods; the latter tests the patience of players who are used to fast action and quick response times. In the absence of such patience, these elements require a high degree of simulation to maintain player interest. This serves as a clear example of why simulation is essential and difficult to achieve in a computer-mediated social interaction environment.

\section{Basic design spirit: Making it fun}

Even though the designers were instructed to consider mimicking real socioeconomic situations as their primary goal, it became increasingly clear that their basic blueprint was strongly influenced by MUDs that were popular in Taiwan at that timefor example, KING OF KINGS (KK) and EASTERN STORY II. Consequently, EC 
came to contain elements of adventure- and riddle-centered games, especially in terms of the jargon used to describe individual episodes. Eventually, EC evolved into a VR rather than a MUD that attempted to simulate social or economic reality. Before long, the EC designers were spending much of their time deliberating how other MUDs handled issues that they had trouble with instead of trying to come up with their own unique strategies. According to Albert, the characteristics of a typical game player encouraged this copycat approach:

Generally speaking, what we are doing is very limited simulation. For example, [in the physical world] we can't determine our appearance. If our MUD follows this rule of reality and automatically assigns certain appearances and other features to characters at the beginning of the game, and if the players can't change the settings easily, they'll abandon their characters by committing suicide and asking for another one until they are satisfied.

In other words, Albert and the other designers became increasingly concerned about keeping features that made EC fun and eliminating features that did not. Fun became a primary rationale behind many design decisions, based on the designers' belief that fun is especially important for games aimed at simulating social reality. To them, a lack of fun translated into the inability to attract enough participants to make certain social and economic interactions successful — for example, business competition. Such shortages could easily result in players taking advantage of system loopholes rather than looking for more legitimate—perhaps more lifelike-ways of making money.

At issue here is whether it is possible to balance the fun factor with the desire to create MUDs that reflect societal interactions as objectively as possible, thus becoming potential teaching tools. To attract more users, a designer needs to take something that might be considered inherently unattractive or boring-for example, a social or economic system-and make it attractive. When challenged to make a game that is both fun and real at the same time, many designers agree with Albert's assertion that a MUD must have some of the same features as some of the more popular commercial games: ${ }^{7}$

To be fun you need excitement, and to be exciting you need fighting. Without direct, faceto-face competition, there will be very few players interested in the game. A fun MUD, such as KK, has to be simple to use. The users just go ahead and slaughter others without thinking.

Another aspect of fun expressed by the designers was the emphasis on equality among players, which is certainly not the case in the real world, and which was fundamentally opposite to our original purpose of creating a game that taught users about gender inequality in an economic society. Because MUDs are considered more as games than simulations, they follow the basic game assumption that all players should have equal starting positions. Consequently, our goal of mimicking gender stratification in society was lost at a very early stage of the design process. We were told later by the designers that players would never willingly participate in a game in which characters are born with unequal statuses: 
Albert: You have both sexes now, but male characters have all the privileges. Then, every player will choose to be a male. Who wants to be a female?

Dave (an undergraduate student designer): Basically, we didn't put too many limitations on the character setting. We let the players develop their own characters. If the system assigns too many attributes, the players will keep re-selecting characters until they are satisfied.

The EC designers also mentioned a design principle associated with the very popular EASTERN STORY II MUD: Gods are impartial. At the beginning of that game, every player receives a fixed amount of value that can be divided among such attributes as physical strength, wealth, and appearance. Tradeoffs are inherent to the game: A player may decide to give up a few years of life in return for a better physical appearance, or give up some money in return for strength. This approach exerted a very strong influence on our design team, despite our instructions that EC should copy the physical world as much as possible. Areas in which inequalities remained included luck and vulnerability - features that could not be decided by players and which therefore were considered relatively innate. Our designers acknowledged that a mix of surface equality and hidden inequality were required to make their MUD more interesting; as Albert said, "Fairness and difference are both necessary for a game of fun." However, they tried to keep the unequal aspect invisible, believing that failing to do so would result in players refusing to join the game.

Further analysis revealed associations among fun-driven factors, risk, and randomness - a finding that is supported by other studies of Internet communities. According to Kollock (1998) and Godwin (1994), a proper mix of risk and crisis is required to establish a successful online community. Thus, fun may be realized via known risks that lack of a sense of reality - for instance, the potential death of a role may represent an extreme level of danger to a character. However, there is a point where unreality can go too far, such as the ease with which suicide can be used to solve problems. The EC designers told us that in $\mathrm{KK}$, characters routinely turned to suicide to get out of bad marriages because divorce was forbidden. Reality is turned upside down in games where death is considered an insignificant event or in games where players can control several lives simultaneously.

\section{Traces of the builders' beliefs}

For designers, it can be difficult to recognize and acknowledge the ways that their personal world visions affect their virtual environments. During interviews, the EC designers frequently discussed the question, "How do players think?" without considering that their answers might actually be more representative of their own viewpoints. Our designers also played other MUDs, and so the boundary between them and EC players was blurred and the dialog between the two sides highly recurrent and influential. The most positive aspect of this crossover was that it allowed designers to place themselves in the players' position when creating their game, as well as to gain some insight into what players want and how they might react. Consequently, the world the 
designers created was a reflection of their membership in a highly homogeneous group.

Certain aspects of the EC-simulated environment are useful for describing the attitudes of many MUD designers-for example, the shared demographics of the EC designers and the predominantly male college students who were their target audience. Our game was unusual in that it had a very narrow target group consisting of science or engineering majors; it was designed to reflect the needs of an economy in which manufacturing industries were given much greater value than service businesses. New characters had to choose between starting a factory or farm when registering to play EC. ${ }^{8}$ When asked to describe their rationale for emphasizing manufacturing, the designers told us that in the initial stage of the game (and, by extension, perhaps the initial stage of an economic system), they considered service industries to be functionally dispensable to the basic operation of a society and that the society must first produce enough goods for trading, which would lead to the development of a stock market, product advertising, and various government services. We later felt that the designers demonstrated limited imagination concerning what constitutes a functionally indispensable job for creating a society, revealing biases that we associated with their training as engineers. That training was also reflected in decisions made concerning production logic - for example, material extraction, assembling, and manufacturing. To simplify the assembly process, the designers decided that all EC products must consist of combinations of five basic elements: water, animals, plants, minerals, and precious metals. For instance, a player who wanted to start a bread factory had to deal in water and plants when purchasing raw materials.

One negative aspect of the designers' engineering backgrounds was their belief that most players would be lacking in basic knowledge concerning the composition of daily life items. As a result, we noted that they made a special effort to reduce the amount of special component knowledge required to produce an item. Nevertheless, the technique-oriented design of the EC business environment sometimes made players without science and engineering backgrounds feel alienated, and perhaps take the game less seriously. For example, formulas for some medicines were determined arbitrarily, giving players the impression that all they had to do was blindly mix some elements in various proportions, make the claim that the product was effective against certain diseases, then sell it at a good price.

The designers' youth and inexperience was also reflected in decisions concerning social relationships among EC players. None of the designers were married, which made discussions about a marriage system very interesting to the married researchers. They told us that they had made an attempt to write one but shied away when reminded of the difficulties in designing KK. One of the two gods of that game, a female, suggested that the wives in KK should be allowed to spend their husbands' money without any restrictions. Her idea was accepted by the other god (who was also her boyfriend), and so married women in KK gained the absolute right to spend their husbands' fortunes. Wives in that game were given the specific right to spend their husbands' money at will as long as their husbands were on the spot. This reflects a lack of knowledge in the compromises that occur within marriage and raises the question of 
whether the same decision would have been made if the two KK gods were male. Our male-dominated design team was reluctant to adopt such an unequal marriage system, and because they could not come up with a more fun alternative, they simply abandoned the idea.

Certain aspects of the EC family system were also very different from what usually happens in the physical world. All EC children are adopted ${ }^{9}$ and, unlike the situation in the average Taiwanese family, are not obligated to take care of their aging parents, even though the parents have to spend a lot of game time raising their children. ${ }^{10}$ On the other hand, EC players held the right to decide whether they wanted to adopt a child; in real Chinese families, the pressure on young married couples to have and raise children is intense.

The lack of balanced resource mobility in EC can be viewed as evidence of the designers' youth and unmarried status. The physical appearances of EC characters also support previous MUD researchers' observations that the idealized bodies found in many virtual environments come from the minds of young males who dominate the composition of most MUD design teams (e.g., see Stone, 1991). Ullman (1995) suggested that White, Californian, teenage masculine ideology is prevalent in computer software programs produced in America. The same ideals can be found in the ways in which love and dating are discussed and presented in many MUDs-further proof that the codes, descriptors, and physical images found in virtual space reflect the worldviews of a very select and limited segment of the general population.

\section{Discussion}

The most important theme to emerge from our interviews with the EC designers centered on the gap that exists between fun and reality in many MUDs. Simply put, if a simulation has a large fun requirement to attract participants, it is clear that more mundane social phenomena - for example, gender and race discrimination, inherited poverty, and other forms of social inequality—must be pushed aside. Whereas most board and computer games, along with amateur sports competition, are based on a principle of equality, many social problems in the physical world result from inequalities between or among groups. It is very difficult to attract players to a simulation focused on such serious issues, and much easier to lure participants to games that are exceptionally unreal and therefore perceived as more fun. Our MUD designers mentioned several ways in which games can be made more fun, including direct competition, born equality, and a strong sense of random luck. Additional research is required to determine a balance between what is real and what is fun before using a game-oriented simulation approach to study social issues or teach social concepts in classrooms.

Another question raised by this analysis is whether assigned participation (as opposed to voluntary participation) is required to establish natural, lifelike computer simulations. This also requires the consideration of certain ethical concerns, as exemplified by Zimbardo's (1972/2001) controversial experiment in which participants were randomly assigned roles as inmates and orderlies in a simulated prison 
environment. ${ }^{11}$ Clearly, computer-mediated simulations are less harmful than social experiments that require physical participation. However, although online participants may feel more comfortable because of their anonymity, they may also feel detached for the same reason - an equally disturbing situation for anyone trying to conduct a valid experiment. Before increasing the use of simulations in research (as well as in classrooms), differences between social experimentation and social simulation need to be clarified.

Voluntary participation raises the issue of self-selection bias. Volunteers who respond to announcements of new online games requiring testing are usually experienced game players. These experienced gamers may not only demonstrate higher standards but also express social values and behaviors that are special to their gaming community. Thus, it becomes difficult to validate any socioeconomic patterns that are observed from their online interactions because they may reflect sets of unwritten behavioral rules that govern the ways that games are played rather than offline realities. This is another facet of the well-known online questionnaire issue that needs to be addressed before computer-mediated simulation can become a legitimate method for studying social issues.

Another finding concerned the status of robots with identities and social roles in simulated worlds-especially interesting because they do not have counterparts in the physical world. Robots can serve several purposes: as additional characters used to increase a game's population, thus making it more attractive to potential participants; as characters that perform routine jobs that are not considered fun by human players; and as a means of providing challenges, dangers, and crises to increase the excitement and fun factor of a game or simulated environment. In many cases, they take on the roles of disadvantaged (unequal) characters in a MUD.

\section{Conclusion}

Hawthorne (1999) argued against the claim that virtual reality is as good as physical reality. In a like manner, simulations can only approach reality, no matter how convincing they might appear on the surface. And as Pournelle (1990) noted, a simulation can be "pretty convincing . . . and that's the problem, because it's a simulation of the designer's theories, not of reality" (p. 110). It is very important to identify and remain aware of all distortions that go into the design of a simulated environment, including those stemming from the designers' implicit values and worldviews. Researchers who want to use simulations to study social phenomena must be alert to the potential dangers associated with any artifact, because it is important to understand the social values and ideologies behind a creator's design decisions whenever artifacts deviate from the real objects they are meant to simulate.

Social reality is, of course, very complex compared to simulated reality, because it is constantly being reconstructed by participants who spend large amounts of time and energy learning social rules and their functions. The time and energy spent on design 
decisions and learning the rules of a simulated reality are minimal by comparison. The result is that the creators of simulated reality games have no choice but to extract some core social principles while discarding a large number of details. During the process of simplification, certain technical constraints may make it hard to preserve the essential principles. As argued by Friedman (1995) and Turkle (1997b), cognition of the highly interlocked complexity of modern social systems increases the doubt that software designers can simulate their component parts.

In other words, we may have to accept the impossibility of simulating a full society and instead be satisfied with somewhat accurate depictions of certain subsystems. Our EC designers found it very difficult to incorporate a relatively small number of subsystems (e.g., education, markets, family, and governments) into a single simulated environment. Yet even after successfully constructing separate subsystem models, there is no guarantee that enough interactive rules have been established to interconnect them. In the physical world, it takes a long time to develop a social system, and few game players have the kind of patience required for that task. Furthermore, we believe that those facets of society that are easiest to simulate are those having a large number of operational rules and models-for example, government elections and stock markets. The fewer the major functioning principles that can be extracted from a phenomenon, the more difficult it becomes to simulate.

Finally, we return to the idea of fun, which seems to be a dominant concept in creating simulations and MUDs. The rules that control interactions within and among social subsystems must take fun into consideration or a simulation will fail to attract participants. Any research involving involuntary participation must be vigorously tested in terms of validity, because anyone can leave a game when it is no longer fun, but participants in a controlled experiment feel compelled to play whether the situation is fun or not. This represents a fundamental constraint for computer-mediated simulation research methodology.

\section{Notes}

1. A simulation game involving gender-based social stratification holds social and educational meaning. Taiwan is certainly a prime example of the gender inequality that still exists in most parts of the world. Combating inequality requires consciousness raising among men and women, that is, establishing awareness of the effects of gender on the social treatment one receives within a larger social context. Role-playing simulation games seem perfect for addressing issues of gender stratification, seeing that role-playing essentially entails putting oneself in another's shoes. Role-taking and role-playing is a popular tool for creating senses of empathy or sympathy toward people with a different status or in different social roles.

However, it can be argued that a role-playing computer simulation game has more to offer than other forms of role-playing to address gender issues. For some ascribed roles (e.g., gender and ethnicity), experiencing alternatives in the physical world requires enormous effort (from men appearing in public in women's clothes all the way to transsexual operations), which tempers the desire of many to experiment with cross-gender or cross-racial roles. The anonymity of an online simulation community minimizes the costs and risks of assuming a new identity. Our greatest hope is that game players could see beyond their taken-for-granted gender worlds and come away with a better understanding of how gender shapes life experiences. 


\section{SIMULATION \& GAMING / March 2003}

2. Of course, the concept of social reality is debatable. We gave the designers just a few general guidelines based on existing studies. For example, resource distribution in Taiwanese families generally favors sons over daughters, meaning that daughters often receive less investment in terms of education. We therefore made the suggestion that female ETERNAL CITY (EC) characters be given less family resources and lower educational statuses than males-implying that such factors as gender, family background, and appearance should be assigned by the system and not be left to the choice of individual players. The designers did not follow this principle, arguing that to make the game fair, players should be given the right to choose their identities. According to one viewpoint, no one would want to play a game in which certain characters were born with lower statuses than their competitors.

3. To attract players, new registrants were given one factory and one warehouse. No tax payments were required for either piece of real estate during the first month of play.

4. In a typical session, "Emily the Pretty Face" enters Minod City. After saying hello to everyone and chatting with some friends, she works on a recipe for a food product she wants to sell, making a small amount of the product with the ingredients she has on hand. She then looks for a store to sell her product and bargains with the owner. Because Minod City is densely populated, she decides to move to the newly established Duma City, where she purchases some land and considers running for mayor. On the road to Duma City she meets a male character who is very rude; he describes how to take advantage of a system loophole to make some easy money. She drinks some water before moving on.

5. In all cases, pseudonyms are used to protect the identities of the interviewees.

6. The designers considered this real and fun.

7. However, according to the experience of James Aspnes, the designer of TinyMUD, this viewpoint may be wrong. TinyMUD emphasizes equality; a scoring system was purposefully left out so that competitiveness would be reduced. Part of the game's original rationale was to always arrive at open endings, thus eliminating the standard practice of ending a game once a character accumulates enough points and/or overcomes a certain number of barriers. The lack of a scoring system resulted in some players leaving because they felt that the lack of a measure for defeating others reduced or eliminated the fun factor. However, TinyMUD did attract some new players who identified with or were curious about the design concept (Rheingold, 1993).

8. Although the designers tried to expand the number and scope of professions for players to choose from in the second and third versions, the overall emphasis still favored manufacturing over service business.

9. The reason for this is that every character needed a player to control it. There were no restrictions on players taking on the roles of their own characters and children at the same time, making it more likely that fortunes/properties would remain in the same family. However, it was believed that having different players control parent/child characters would make the game more real and more fun.

10. Of course, this is in the context of Asian societies. For instance, Chinese emphasize the responsibility of adult children to give emotional and material support to their parents.

11. Some roles in Zimbardo's (2001) experiment included requirements to physically or verbally threaten prisoners - clearly tasks that could not be considered fun. Zimbardo found that the longer the participants stayed in the simulated environment, the more seriously they viewed their roles, in some cases to degrees that profoundly affected and shocked them.

\section{References}

Artzrouni, M., \& Gouteux, J.-P. (2001). Population dynamics of sleeping sickness: A microsimulation. Simulation \& Gaming, 32(2), 215-227.

Benedikt, M. (2000). Cyberspace: First steps. In D. Bell \& B. M. Kennedy (Eds.), The cyberculture reader (pp. 29-44). London: Routledge.

Edward, N. S. (1997). Computer based simulation of laboratory experiments. British Journal of Educational Technology, 28(1), 51-63. 
Friedman, T. (1995). Making sense of software: Computer games and interactive textuality. In S. G. Jones (Ed.), Cybersociety: Computer-mediated communication and community. Retrieved from http:// www.duke.edu/ tlove/simcity.htm

Gilbert, N. (1999). Simulation: A new way of doing social science. American Behavioral Scientist, 42(10), 1845-1847.

Godwin, M. (1994, June). Nine principles for making virtual communities work. Wired, 2, 72-73.

Gonzalez, J., \& Gross, D. L. (1995). Learning tactics from a sports game-based simulation. International Journal of Computer Simulation, 5(2), 127-148.

Hawthorne, S. (1999). Cyborgs, virtual bodies and organic bodies: Theoretical feminist responses. In S. Hawthorne \& R. Klein (Eds.), CyberFeminism: Connectivity, critique \& creativity (pp. 213-249). North Melbourne, Victoria, Canada: Spinifex.

Holland, J. H., \& Miller, J. H. (1991). Artificial adaptive agents and economic theory. American Economic Review, 81, 365-370.

Johnson, P. E. (1999). Simulation modeling in political science. American Behavioral Scientist, 42(10), 1509-1530.

Kollock, P. (1998). Design principles for online communities. PC Update, 15(5), 58-60. Retrieved from http://research. microsoft.com/scg/papers/KollockPrinciples.htm

Pournelle, J. (1990, February). Computing at Chaos Manor: Optical disk daze. BYTE, 15(2), 99-114.

Rheingold, H. (1993). The virtual community: Homesteading on the electronic frontier. Reading, MA: Addison-Wesley.

Stone, A. R. (1991). Will the real body please stand up? Boundary stories about virtual cultures. In M. Benedikt (Ed.), Cyberspace: First steps (pp. 81-118). Cambridge, MA: MIT Press.

Stuart, R. (1996). The design of virtual environment. New York: McGraw-Hill.

Timpone, R. J., \& Taber, C. S. (1998). Simulation: Analytic and algorithmic analyses of Condorcet's paradox - Variations on a classical theme. Social Science Computer Review, 16(1), 72-95.

Turkle, S. (1997a). Constructions and reconstructions of self in virtual reality: Playing in the MUDs. In S. Kiesler (Ed.), Culture of the Internet (pp. 143-155). Mahwah, NJ: Erlbaum.

Turkle, S. (1997b). Life on the screen: Identity in the age of the Internet. New York: Touchstone.

Ullman, E. (1995). Out of time: Reflections on the programming life. In J. Brook \& I. A. Boal (Eds.), Resisting the virtual life: The culture and politics of information (pp. 131-143). San Francisco: City Lights.

Zimbardo, P. G. (2001). The pathology of imprisonment. In J. M. Henslin (Ed.), Down to earth sociology (pp. 272-277). New York: The Free Press. (Original work published 1972)

Zola, J., \& Ioannidou, A. (2000). Learning and teaching with interactive simulations. Social Education, 64(3), 142-145.

Holin Lin is a professor of the Department of Sociology at National Taiwan University. She received her PhD in sociology from the University of California at Davis in 1995. Her major research interests are computer-mediated communication, technology and society, and gender studies. She has written on the social aspects of information technology, including social movements on the Internet, digital divide, and new media ethics. She participated in a 3-year interdisciplinary project on Information Technology and Social Change sponsored by the National Science Council, Taiwan.

Chuen-Tsai Sun received his BS in electrical engineering (1979) and his MA in history (1984) from National Taiwan University. He received his PhD in computer science from the University of California at Berkeley in 1992. From 1991 to 1992 he was with the Lawrence Livermore National Laboratory, California, where he participated in research projects on fuzzy neural networks. Since 1992 he has been with National Chiao Tung University, Taiwan, where he is a professor in the department of computer and information science. He is currently engaged in research and teaching in the areas of creative evolutionary systems, Web-based collaborative learning, and computer simulation in social studies. He is also in charge of two community universities in Hsinchu City, Taiwan. 


\section{SIMULATION \& GAMING / March 2003}

ADDRESSES: HL: Department of Sociology, National Taiwan University, 1 Roosevelt Road, Section 4, Taipei, 10639, Taiwan; telephone: +886 (2)23630231-3531; fax: +886 (2)23683531; e-mail: holin@ccms.ntu.edu.tw.CTS: Department of Computer and Information Science, National Chiao Tung University, Hsinchu, 30050, Taiwan; telephone: +886 (3)5731972; fax: +886(3)5721490; e-mail: ctsun@cis.nctu.edu.tw. 